\title{
CALCANEO-FIBULAR ABUTMENT FOLLOWING CRUSH FRACTURE OF THE CALCANEUS
}

\author{
John F. St C. Isbister, Glasgow, Scotland \\ From the Glasgow Royal Infirmary
}

In the most severe type of fracture of the calcaneus that part of the bone lying below the talus is extensively comminuted. When the lateral cortex bursts, fragments may be displaced to lie below the tip of the lateral malleolus, and if they unite in that position the patient may complain of persistent pain at the site. In some cases the pain is the result of actual bony contact between the tip of the fibula and the lateral bulge of the calcaneus-hence the term abutment; in others it appears to be due to compression of the peroneal tendons in the gap between the bones.

Clinically the heel is visibly broadened; a bony mass is palpable below the lateral malleolus, with local tenderness. An antero-posterior radiograph shows the mass and its proximity to the malleolus (Fig. 1). The ankle should not be plantar-flexed when this view is taken so as to avoid superimposition of the tuberosity of the calcaneus.

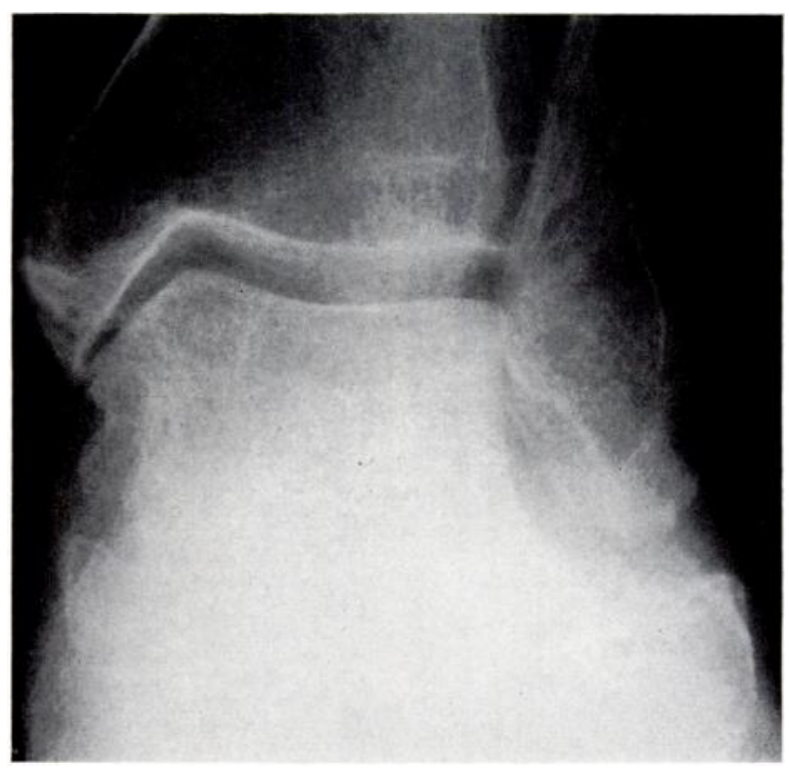

Fig. 1

Case 2 -A radiograph showing true abutment.

In such injuries there is always extensive disruption of the subtalar joint. However, the severity of the disruption often leads to a fibrous ankylosis so firm that the pain from this source is minimal or absent. Both causes of pain may of course be present at the one time.

\section{MANAGEMENT}

Previously the surgical treatment of this complication has been excision of the displaced bone (Cabot and Binney 1907, Cotton 1921, Magnuson 1923). In these reports twenty-one patients were treated in this way, with nineteen successful results. Resection of the tip of the 
fibula was chosen as the treatment for the patients reported here because it seemed a simpler method. This procedure, together with removal of the peroneal tendons from their sheath, was reported by Evans in 1968 as having been used occasionally in the management of this condition, but no results were published.

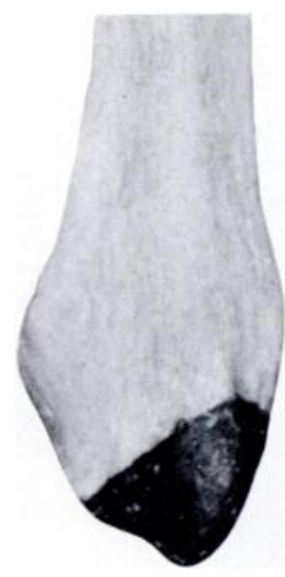

FIG. 2

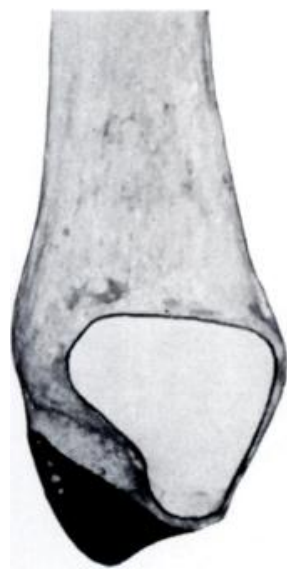

To show the lateral and medial aspects of the lower end of the left fibula. The amount of bone removed is indicated in black. The excised portion does not include any of the articular facet.
Technique of operation-The lateral malleolus is exposed through a longitudinal incision. A similar incision is made in the periosteum and in the calcaneo-fibular ligament, which is split in the line of its fibres. Approximately one centimetre of the tip of the fibula is then excised subperiosteally, the line of resection sloping obliquely downwards and forwards and avoiding the lower articular surface (Fig. 2). The incision in the ligament is closed with absorbable sutures. A plaster cast is not required and the patient may be able to return home the following day. The lateral stability of the ankle is not adversely affected because the periosteum is strong at that point and the attachment of the lateral ligament to it is not disturbed.

\section{CASE REPORTS}

\section{Calcaneo-fibular abutment}

Case 1-A ship's cook aged forty-two, who had sustained a fracture of the calcaneus fifteen months previously, complained of pain over the lateral malleolus. Triple arthrodesis was considered but abutment of the displaced calcaneal bone against the fibula was noted radiographically. The tip of the fibula was excised. The patient reported relief of pain before leaving hospital six days later, and went back to sea after two months. He remains completely free of lateral pain, the only residual symptom being infrequent slight pain medially.

Case 2-A plumber aged forty-nine sustained a crush fracture of the calcaneus involving the subtalar and calcaneo-cuboid joints. Laterally displaced bone was noted in the radiographs (Fig. 3) but was not reduced. At that time there was clearly no contact between fibula and calcaneus. Eight months after injury triple arthrodesis was performed for persistent pain. Four months later the arthrodesis was sound but the patient complained that the pain felt laterally was even worse than before. Radiographs now showed calcaneo-fibular abutment (Fig. 1). The tip of the lateral malleolus was resected, giving relief within two weeks. The patient has returned to work but still has occasional moderate pain on the medial side.

Case 3-A window cleaner aged thirty fell and fractured the right calcaneus extensively. In addition there were fractures of the lower ends of the opposite tibia and fibula involving the ankle joint, which were fixed internally. The right calcaneus was manipulated, a Steinmann's pin in the tuberosity

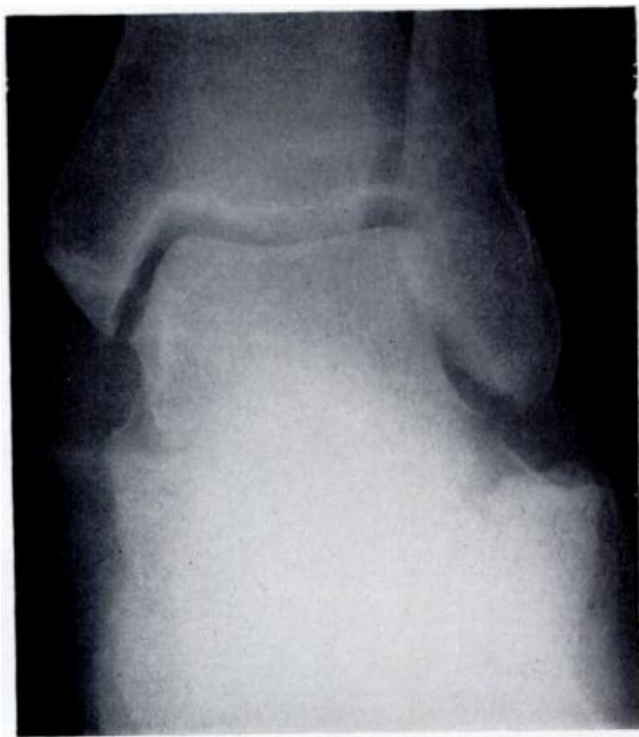

Fig. 3

Case 2-An antero-posterior radiograph of the original fracture showing calcaneal bone laterally displaced but not in contact with the fibula. See also Figure 6.

VOL. 56 B, NO. 2, MAY 1974 


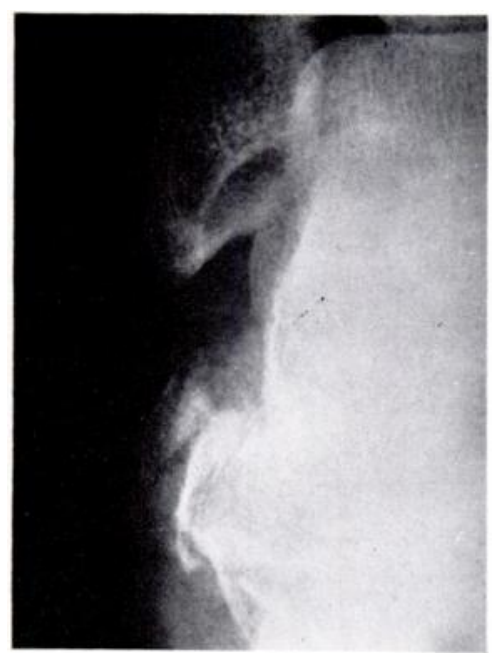

FIG. 4

Case 3-An antero-posterior view of the area below the right lateral malleolus at the time of injury. The laterally displaced calcaneal bone is clearly seen but is not in contact with the fibula.

was not found but the peroneal tendons were seen to be the injury to the left ankle he was not able to return to work until eight months after operation. He still has some discomfort over the outer side of the right ankle.

Case 5-A demolition worker aged twenty-five sustained bilateral calcaneal fractures. On the left there was not much lateral displacement but the tuberosity was split and displaced horizontally; manipulative reduction was needed to avoid skin necrosis. The right calcaneus was very comminuted, the posterior facet being driven down into the underlying cancellous bone. This was treated simply by bed rest for three weeks.

At six months he complained of persistent pain on the right side. Clinically and radiologically there was prominence of the displaced calcaneal mass under the lateral malleolus. At operation two months later compression of the peroneal tendons was found without actual bony contact. The excision of the tip of the fibula completely relieved the lateral pain but there is still some pain medially. He has not yet returned to work, but not because of the right ankle.

The main features of the five cases are given in Table I.

\section{DISCUSSION}

The patients reported here would probably have avoided this complication if the lateral displacement of calcaneal bone had been reduced at the time of injury. Abutment is most

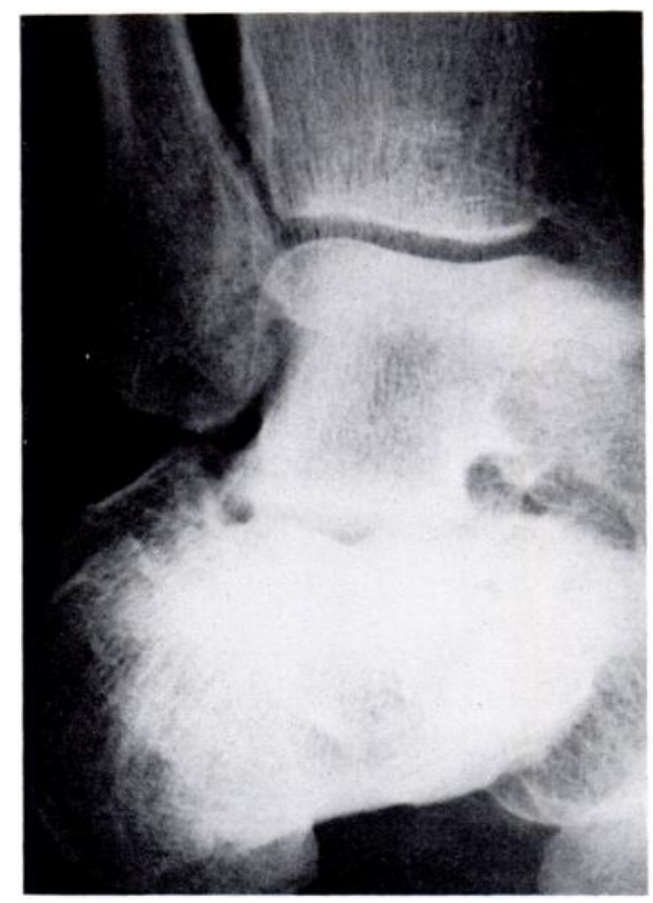

FIG. 5

Case 4-An oblique view of the right ankle after resection of the tip of the lateral malleolus.

likely to arise in the type of fracture where the posterior facet is driven down into the cancellous bone (Fig. 6), and in this variety open reduction and elevation has been recommended (Palmer 
TABLE I

Detalls of the Series

\begin{tabular}{|c|c|c|c|c|c|c|c|c|}
\hline $\begin{array}{c}\text { Case } \\
\text { number }\end{array}$ & $\underset{\text { (years) }}{\text { Age }}$ & $\begin{array}{c}\text { Other } \\
\text { serious injuries }\end{array}$ & $\begin{array}{l}\text { Initial } \\
\text { management } \\
\text { of the fracture }\end{array}$ & $\begin{array}{c}\text { Triple } \\
\text { arthrodesis }\end{array}$ & $\begin{array}{c}\text { Time from injury } \\
\text { to minor operation } \\
\text { (months) }\end{array}$ & $\begin{array}{l}\text { Calcaneo- } \\
\text { fibular } \\
\text { contact }\end{array}$ & $\begin{array}{l}\text { Length of } \\
\text { follow-up } \\
\text { (months) }\end{array}$ & $\begin{array}{l}\text { Residual } \\
\text { lateral } \\
\text { pain }\end{array}$ \\
\hline 1 & 42 & None & Conservative & - & 26 & Yes & 26 & - \\
\hline 2 & 49 & None & Conservative & Yes & 14 & Yes & 13 & - \\
\hline 3 & 30 & Opposite ankle & Manipulation & Yes & 33 & Yes & 8 & - \\
\hline 4 & 23 & Opposite ankle & $\overline{\text { Conservative }}$ & - & 6 & - & 9 & Slight \\
\hline 5 & 25 & Opposite calcaneus & Conservative & - & 8 & - & 6 & - \\
\hline
\end{tabular}

1948, Essex-Lopresti 1952). Closed manipulation and plaster fixation incorporating a spike in the tuberosity has also been advised (Essex-Lopresti 1952, Howat 1966), and remodelling of the calcaneus with a mallet (Cotton 1921). However, conservative management is reported to give generally satisfactory results (Barnard and Odegard 1970), and is the standard method followed in this Department. Closed reduction may not be successful, as in Case 3, and even

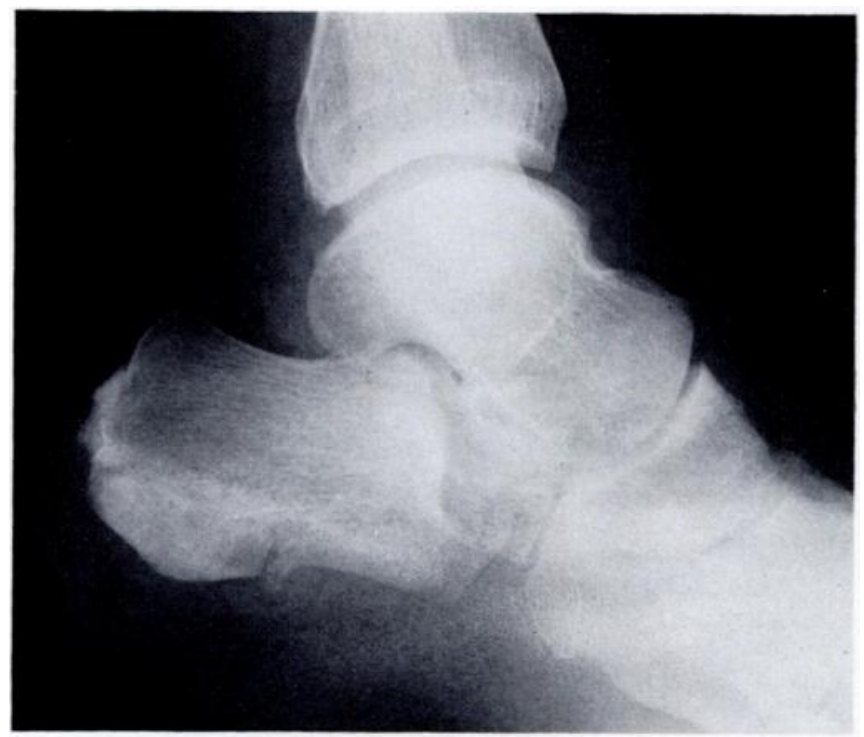

FIG. 6

Case 2-A lateral radiograph showing the type of fracture of the calcaneus likely to result in abutment.

open reduction will not avoid the complication unless care is taken to reduce or remove the displaced calcaneal bone. The condition may therefore be seen not infrequently. Indeed, four of the five cases reported here were seen within the course of a year.

Primary subtalar arthrodesis for severe fracture of the calcaneus has been advocated (Gallie 1943, Hall and Pennal 1960), and primary triple arthrodesis also (Thompson and Friesen 1959). Like open reduction, these procedures would fail to avert the condition if the lateral calcaneal mass were left undisturbed. Removal of subtalar cartilage and bone may indeed decrease the gap between the fibula and the calcaneal bulge and so favour abutment. The patients in Cases 2 and 3 had both undergone triple arthrodesis, and the former actually 
had more pain after this operation. Although their initial radiographs clearly show an appreciable gap (Figs. 3 and 4), bone to bone contact was found at operation in both patients. The gap between the bones might also be reduced by too early weight-bearing and by the formation of new bone in the course of healing of the fracture.

It is therefore important not to ascribe the source of pain to the subtalar joint. If both sources of pain are thought to be present, it is worth while excising the tip of the fibula first to see if this gives relief before embarking on subtalar arthrodesis or triple arthrodesis.

\section{SUMMARY}

1. In a severe crush fracture of the calcaneus part of the lateral cortex may be displaced to lie under the tip of the lateral malleolus. This may cause local pain and tenderness, either by direct bony abutment or by compression of the peroneal tendons.

2. Such pain is usually relieved by excision of the tip of the lateral malleolus, a minor procedure.

3. Four of the five patients reported were completely relieved of lateral pain, and the fifth has only slight residual discomfort.

4. It is important to be aware of this lesion and not to advise subtalar or triple fusion when simple excision of the tip of the fibula would suffice.

I wish to thank Mr T. S. Mann for his advice on the preparation of this report.

\section{REFERENCES}

BARnARD, L., and Odegard, J. K. (1970): Conservative approach in the treatment of fractures of the calcaneus. Journal of Bone and Joint Surgery, 52-A, 1689.

Савот, H., and Binney, H. (1907): Fractures of the os calcis and astragalus. Annals of Surgery, 45, 51-68.

Cotton, F. J. (1921): Old os calcis fractures. Annals of Surgery, 74, 294-303.

Corton, F. J. (1921): Os calcis fracture; remodelling with mallet. Surgical Clinics of North America, 1, 917-918.

EsSeX-Lopresti, P. (1952): The mechanism, reduction technique, and results in fractures of the os calcis. British Journal of Surgery, 39, 395-419.

Evans, D. (1968): Fractures of the calcaneus. Report of Proceedings, British Orthopaedic Travelling Club, Killarney. Journal of Bone and Joint Surgery, 50-B, 884.

GALLIE, W. E. (1943): Subastragalar arthrodesis in fractures of the os calcis. Journal of Bone and Joint Surgery, 25, 731-736.

Hall, M. C., and Pennal, G. F. (1960): Primary subtalar arthrodesis in the treatment of severe fractures of the calcaneum. Journal of Bone and Joint Surgery, 42-B, 336-343.

Howat, T. W. (1966): Fractures. Report of Proceedings, North American Travelling Fellows. Journal of Bone and Joint Surgery, 48-A, 386.

MAGNUSON, P. B. (1923): An operation for relief of disability in old fractures of os calcis. Journal of the American Medical Association, 80, 1511-1513.

Palmer, I. (1948): The mechanism and treatment of fractures of the calcaneus. Open reduction with the use of cancellous grafts. Journal of Bone and Joint Surgery, 30-A, 2-8.

Thompson, K. R., and Friesen, C. M. (1959): Treatment of comminuted fractures of the calcaneus by primary triple arthrodesis. Journal of Bone and Joint Surgery, 41-A, 1423-1436. 